\title{
GESTÃO DE EAD: A IMPORTÂNCIA DA VISÃO SISTÊMICA E DA ESTRUTURAÇÃO DOS CEADs PARA A ESCOLHA DE MODELOS ADEQUADOS
}

\author{
Luis Otoni Meireles Ribeiro, PPGIE-UFRGS, CEFET-RS, luis.otoni@terra.com.br \\ Maria Isabel Timm, CESUP-UFRGS, betatimm@ufrgs.br \\ Milton Antonio Zaro, PPGIE-UFRGS, zaro@ufrgs.br
}

\begin{abstract}
Resumo: Este artigo apresenta relato de experiências e reflexões sobre a importância da estruturação de um setor para desenvolver instrumentos de planejamento e gestão dos cursos a distância, de acordo com necessidades específicas da instituição, levando-se em conta múltiplos cursos, públicos e níveis, bem como a gestão dos clientes internos da instituição (equipe de professores, produtores de mídia, tutores, etc.). São apresentados modelos de cursos à distância para situações diferenciadas, em especial para a educação profissional e tecnológica e o ensino de engenharia. A educação a distância, quando trabalhada numa perspectiva de economia de escala, pressiona por uma abordagem profissional de gestão, a qual pressupõe, além de infraestrutura tecnológica, um planejamento eficaz, dinâmico e adequado frente às demandas de atendimento dos clientes externos e internos de uma IES.
\end{abstract}

Palavras-Chave: educação a distância, educação profissional, educação tecnológica, ensino de engenharia, ensino de ciência e tecnologia.

Abstract: This paper summarizes experiments report and reflections about the importance of creating a local distance education structure in each university, to develop tools and strategic planning, focused on the specific needs of the institution, like multiple courses, publics and levels, as well as internal clients (teachers team, media production team, tutors, etc.). Models of distance courses are presented, for different situations, mainly for professional and technological and engineering education. Distance education, in a scale prospective, requires professional approaches, besides technological infrastructure, including dynamic, efficient and adequate planning to support internal and external university client's demands.

Key-Words: distance learning, vocacional education, technological education, engineering education, scientific and technology educacion.

\section{Introdução: importância de um CEAD}

A educação a distância (EAD), que no seu formato convencional já tem mais de um século, foi revigorada com o uso dos computadores e da internet, ao longo da última década. Além disso, atividades viabilizadas pela EAD contemporânea também podem ter caráter de apoio extraclasse, permitindo ao professor presencial continuar sua atividade de ensino, resolvendo problemas de calendário escolar, carga horária de disciplinas, ou até mesmo, vencer conteúdos programáticos extensos. Hoje, vários educadores se valem do recurso da internet para programar estudos e atividades para os alunos, agendando atendimentos virtuais via programas de mensagem instantânea ou fóruns de discussão em ambientes virtuais de aprendizagem - AVAs, pedindo que os alunos enviem trabalhos por e-mail, para posterior correção. As tecnologias de informação e comunicação - TICs passaram a ser incorporadas ao arsenal de atividades pedagógicas sem que os docentes percebam que estão educando a distância. Na educação profissional e tecnológica e no ensino de engenharia também se acompanha um crescimento do uso pelos estudantes, fora do horário normal de aula, de 
softwares de projeto auxiliado por computador - CAD, e de suas extensões para engenharia CAE e manufatura - CAM, assim como de simuladores de projetos e circuitos elétricos, eletrônicos, pneumáticos, enfim de automação em diversos níveis (Ribeiro et al., 2005) (Ribeiro et al., 2006).

A elaboração de programas de educação a distância para um grande número de estudantes encerra desafios relacionados às necessidades de logística, suporte de tutoria, produção de material e etc. Ao pensar-se em termos de escala, projetos com milhares de alunos, abandonam-se as experiências fragmentadas ou isoladas, ou o amadorismo (soluções improvisadas) com que muitas equipes permitem-se trabalhar, seja por trabalharem com um número reduzido de alunos ou por estarem nos primeiros estágios da EAD dentro da organização escolar, em fase de adoção de políticas de fomento e de diversidade de experiências de EAD1.

A educação a distância, quando trabalhada numa perspectiva de economia de escala, própria das instituições particulares de ensino, pressiona por uma abordagem profissional de gestão, a qual pressupõe, além de infra-estrutura tecnológica, um planejamento eficaz, dinâmico e adequado frente às demandas de atendimento, não só dos clientes externos (alunos e comunidade), como relativas às necessidades de coordenação e satisfação dos clientes internos (docentes e equipe técnico-pedagógica).

Não se trata, portanto, apenas de infra-estrutura tecnológica, declaração de princípios pedagógicos e de um local físico devidamente identificado, mas de um ponto de referência institucional que norteie e agregue os recursos de planejamento e desenvolvimento da educação a distância, com critérios claros de planejamento e gestão, bem como instrumentos para acompanhar e coordenar cada etapa do trabalho.

A implantação de um Centro de Educação a Distância - $\mathrm{CEAD}_{2}$ - tem sido procedimento comum das instituições educacionais, como órgão capaz de cumprir esta função no processo de gestão. Contudo, ainda existem desafios enormes a serem superados na implantação efetiva de um CEAD. O primeiro deles se refere à estruturação e planejamento estratégicos que, realmente, dêem conta de atender aos clientes internos do CEAD, os professores, tutores, equipes de produção de mídias, suporte técnico e gestores, que estarão na linha de frente durante os primeiros meses do funcionamento do CEAD, quando estão sendo criados os programas, cursos e materiais de educação a distância. Além disso, o sucesso na estruturação destes centros influencia diretamente o sucesso do atendimento dos clientes externos, uma vez que estes profissionais deverão ser capazes de compreendê-las, equacionálas de forma eficiente, otimizar recursos e garantir a sustentabilidade do projeto, em larga escala e longo tempo.

A problemática central de um CEAD está relacionada à dificuldade de elaborarse, de forma científica, um plano de trabalho para o Centro que, realmente, atenda as necessidades de todos os clientes (internos e externos). As indefinições são muito amplas, principalmente para os CEADs que iniciam suas atividades, os quais precisam identificar suas prioridades, desde a estruturação de pólos até a identificação do melhor modelo de negócios para ofertar aos parceiros, passando pela identificação de

1 Normalmente, as instituições iniciam suas atividades de EAD sem uma idéia clara ou completa de todos os desafios, ou da natureza de todas as demandas a serem atendidas. Grande parte das instituições reúne sua equipe em função das competências já existentes na instituição, baseando-se na experiência de educadores e gestores que trabalharam previamente com educação a distância, ou trazendo profissionais externos com experiência para se juntar a equipe. Em qualquer um dos casos, são necessárias ações expressivas de capacitação da equipe, tanto pela natureza da atividade quanto pela sua própria característica multidisciplinar, incluindo professores e futuros tutores.

2 Será usado CEAD neste artigo, como uma forma geral de designação de setor encarregado da EAD na instituição, embora existam organizações com estas funções chamadas núcleos, departamentos, entre outros nomes. 
prioridades na capacitação de todos os atores envolvidos nos processos. Essas e muitas outras questões têm sido resolvidas com base na experiência pessoal dos gestores da

EAD, sem que alguma metodologia científica tenha sido empregada para auxiliar nesse sentido. O primeiro dos autores deste artigo está desenvolvendo tese de doutorado onde aplica uma metodologia de trabalhoz robusta o suficiente para permitir levantar as demandas de qualidade do serviço a ser prestado por um CEAD e ajudar a se estabelecer as prioridades de ação do Centro, o que permitiria uma gestão eficiente de recursos humanos e financeiros, além de uma implementação da educação a distância com um enfoque profissional e de qualidade.

Instituições privadas e públicas investem na educação a distância geralmente preocupando-se com a escolha do ambiente de aprendizagem e com as tecnologias a serem adotadas. Enquanto umas direcionam esforços na montagem de um sistema de transmissão via satélite e organizam seus cursos em função desta solução tecnológica, por exemplo, outras dão ênfase à escolha de uma plataforma de EAD, seja comprando, produzindo ou apropriando-se de soluções livres, como o Moodle4 e Teleduc5.

Entretanto, muito mais do que escolha tecnológica ou plataforma, o planejamento e execução de um projeto de educação a distância requerem um trabalho de organização detalhado, que se desdobra em inúmeras tarefas, com suas particularidades. As exigências variam de acordo com a natureza do curso, o tipo de aluno, as tecnologias envolvidas, entre outros itens, ou seja, o desenho de um curso de educação a distância irá variar de acordo com as demandas, as quais são dinâmicas e se alteram ao ritmo das múltiplas situações. Isto impede que uma instituição educacional possa construir uma solução única de EAD que dê conta de todos os problemas existentes em educação a distância.

“(...) É preciso construir soluções que dêem conta das questões que inter-relacionam (positiva ou negativamente, dependendo do caso) as necessidades do ensino de conteúdos complexos com a economia de escala envolvida na gestão de EAD." (Perry et al, 2006)

De acordo com o porte da instituição de ensino ou de sua abrangência e diversidade de atuação, uma solução única pode não mostrar-se adequada. A tendência maior é a de serem adotados desenhos diversos de cursos a distância e esta diversidade de soluções de EAD pressiona para a necessidade de um domínio de todas as etapas de produção e operação de um curso a distância. Principalmente quando a instituição trabalha com variados níveis e tipos de educação profissional e/ou ensino superior, cresce a exigência de desenhos de cursos a distância que contemplem e atendam essas demandas particulares. Assim, uma mesma instituição de ensino poderá ter cursos na modalidade a distância com características diferenciadas, baseadas em suportes midiáticos e de tipos de interação distintos, com estruturas de tutoria diversas e com logísticas de aulas, estratégias pedagógicas e professores diferenciados.

3 Trata-se da metodologia Quality Function Deloyment - QFD (Desdobramento da Função Qualidade) a ser implantada no Centro de Educação a Distância - CEAD de uma instituição de ensino superior. Com o objetivo de mapear os requisitos de funcionamento com qualidade do CEAD, desdobrando as matrizes em todas as fases, do projeto, produção e operação de soluções de EAD (Cheng \& Filho, 2007).

4 Moodle (Modular Object Oriented Dynamic Learning Enviroment) - é um sistema de gerenciamento de aprendizagem (LMS - Learning Management System) ou ambiente virtual de aprendizagem de código aberto, livre e gratuito. Acesso em: http://www.edutools.info/course/productinfo/

5 TelEduc - É um ambiente para a criação, participação e administração de cursos na Web, desenvolvido por pesquisadores do NIED (Núcleo de Informática Aplicada à Educação) da UNICAMP. Acesso em:

http://www.nied.unicamp.br/ 
Nesse sentido, conhecer todos os aspectos da gestão da EAD é requisito essencial para que a mesma seja desenvolvida de forma profissional e com qualidade.

Entretanto, as pesquisas em curso sobre a EAD normalmente privilegiam alguns aspectos em relação a outros, como por exemplo o modelo pedagógico em relação às necessidades de comunicação entre equipes, ou as necessidades de critérios claros de avaliação de cada membro da equipe, itens que podem ser percebidos e gerenciados através de uma visão sistêmica sobre a gestão da EAD (Moore \& Kearsely, 1996).

\begin{abstract}
Sugere-se que, até agora, a maior parte deles tenha contemplado questões muito específicas das diversas disciplinas que integram o contexto multidisciplinar da gestão de EAD, ora de caráter pedagógico, ora de caráter tecnológico. Acredita-se que este posicionamento - de pesquisa e de gestão - frente aos inúmeros desafios colocados, apenas resolvem problemas pontuais, sem apontar para a necessidade do aporte de outras áreas do conhecimento - como a gestão de processos -, nas investigações, que darão suporte a futuros projetos que possam compreender o sistema como um todo, para melhor compreender a inter-relação das partes. (Perry et al, 2006)
\end{abstract}

No contexto da estruturação dessa visão sistêmica, obrigatória no desenvolvimento de um processo profissional e sustentável de gestão, cresce a importância de estruturas como o CEAD para viabilizar o projeto institucional de EAD e prover os elementos que vão dar suporte a esse tipo de gestão. Estes centros seriam os órgãos das IES formados por uma equipe multidisciplinar de professores, técnicos, pesquisadores e, eventualmente, bolsistas (caso das universidades federais, no Brasil).

Normalmente, este setor deverá ter por atribuições coordenar, co-orientar e coexecutar atividades de ensino, pesquisa e extensão ligadas à área de educação a distância, em sintonia com as normas institucionais e legais. Cabe também ao CEAD a responsabilidade de capacitar, técnica, pedagógica e cientificamente, os profissionais ligados à EAD e sugerir políticas tecnológicas institucionais. Por fim, é responsável por manter uma infra-estrutura técnica, operacionalmente voltada ao apoio do processo de ensino-aprendizagem a distância. $\mathrm{O}$ nome dado a esta estrutura dentro das IES pouco importa. A verdade é que o CEAD, NEAD, CINTED, NUTED e outras denominações, constituem-se como pontos de referência para as ações de educação a distância a serem desenvolvidas na instituição de ensino.

A estrutura de um centro de educação a distância não obedece a parâmetros rígidos, mas todos se caracterizam por mobilizar equipes multidisciplinares para a EAD.

Entretanto, essas são comumente as atribuições do Centro de Educação a Distância:

- coordenar, co-orientar e co-executar atividades de ensino, pesquisa e extensão ligadas à área de Educação a Distância;

- monitorar o desempenho da infra-estutura e dos meios tecnológicos disponíveis na IES, passíveis de serem utilizados em atividades de Educação a Distância;

- planejar e executar um plano de ação de EAD;

- capacitar, técnica e cientificamente, os profissionais ligados à área de Educação a Distância da IES, em uma estrutura multicampi e de outras entidades ou instituições;

- criar e manter um grupo de apoio ao ensino, à pesquisa e à extensão na área de Educação a Distância;

- sugerir políticas tecnológicas institucionais para o bom desempenho da

Educação a Distância na IES, bem como coordenar a execução das políticas aprovadas pelos órgãos superiores da instituição;

- manter uma infra-estrutura técnica, operacionalmente voltada ao apoio do processo de ensino-aprendizagem a distância;

- articular esforços com o setor de avaliação institucional para encontrar mecanismos adequados de avaliação da Educação a Distância na IES; 
- integrar-se com outros órgãos públicos e privados.

Como é possível observar, o papel de um CEAD é insubstituível, mas o tempo para o desenvolvimento e implantação de um núcleo de EAD é elevado. A maioria dos gestores de instituições educacionais encontra dificuldades em perceber o que Freeman

(2003) explica com propriedade:

"Gerir uma instituição de EAD requer uma diversidade de conhecimentos muito maior do que gerir uma escola, um liceu ou uma universidade, e, no seu todo, não será possível recrutar pessoal com estes conhecimentos. A instituição terá de desenvolver o seu próprio pessoal, até que ele atinja a diversidade e profundidade de conhecimentos necessários. Realisticamente, isto demora o seu tempo, e não será exagero dizer que uma nova instituição de EAD precisa de 2 a 5 anos até que o núcleo do seu pessoal atinja o pleno da sua capacidade operacional." (p.11)

Estabelecer um cenário completo e detalhado de funções, atividades, prioridades funcionais e ações estratégicas pode ser a diferença entre um programa de EAD viável economicamente ou de prejuízo institucional. Apesar das instituições públicas no Brasil não sofrerem a mesma pressão das particulares sobre o retorno dos investimentos financeiros, é possível analisar suas estruturas de CEAD, em virtude da trajetória histórica da EAD.

Algumas questões, que raramente aparecem nas análises acadêmicas, se impõem com relação a este desafio:

- Qual é a estrutura de CEAD mais adequada?

Centro?

- Quais são os profissionais que devem fazer parte da equipe multidisciplinar do

- Quais são os serviços que devem ser prestados pelo CEAD para o funcionamento e implantação da EAD numa perspectiva institucional?

- Quais são as ações prioritárias a serem desenvolvidas pelo CEAD para que seus clientes internos tenham suas demandas atendidas e possam prestar um serviço de qualidade?

$\mathrm{Na}$ busca de respostas a essas perguntas, alguns aspectos comuns começaram a ser identificados a partir da experiência prática, além da pesquisa bibliográfica6. O CEAD da Universidade de Brasília - UNB pode ser considerado um bom exemplo de estrutura, conforme a Tabela 1. Este CEAD atua desde 1979, adotando diretrizes e desenvolvendo ações inovadoras que auxiliem a aprendizagem. Este Centro tem sido responsável, principalmente, pela oferta de cursos de extensão universitária e de especialização, atendendo às necessidades de diversos segmentos da sociedade que necessitam de saídas educacionais que possibilitem flexibilização de tempo e espaço para aprendizagem.

Tabela 1 - Estrutura do CEAD - UNB.

\begin{tabular}{|l|l|}
\hline \multicolumn{2}{|c|}{ Estrutura do CEAD - UNB } \\
\hline \multicolumn{1}{|c|}{ Setores } & \\
\hline Diretoria & Diretor \\
\hline \multirow{2}{*}{ Coordenação Executiva - COE } & Coordenador executivo \\
\cline { 2 - 2 } & Gestor administrativo \\
\hline Secretaria Executiva - SEC & Secretária executiva \\
\hline \multirow{2}{*}{ Coordenação Acadêmica - COA } & Coordenadora pedagógica \\
\cline { 2 - 2 } & Equipe de desenvolvimento de projetos científicos \\
\hline \multirow{3}{*}{ Assessoria - ASS } & Assessoria jurídica \\
\cline { 2 - 2 } & Analista de projetos \\
\cline { 2 - 2 } & Assessora de relaçōes interinstitucionais \\
\hline
\end{tabular}

${ }_{6}$ Os autores vêm trabalhando há quase uma década na área de planejamento, produção e validação de projetos de EAD. 


\begin{tabular}{|c|c|}
\hline \multirow{6}{*}{ Unidade de Pedagogia - UPE } & Gerente da unidade pedagogia \\
\hline & Equipe de produção \\
\hline & Equipe de Orientação e Acompanhamento Pedagógico \\
\hline & Equipe de avaliação \\
\hline & Equipe de suporte e tutoria \\
\hline & Segurança \\
\hline \multirow{4}{*}{ Unidade de Tecnologia - UTE } & Gerente da unidade de tecnologia \\
\hline & Equipe de Administração de Redes e Apoio Tecnológico \\
\hline & Equipe de Suporte ao Usuário e Manutenção de Equipamentos \\
\hline & Equipe de Desenvolvimento de Sistemas \\
\hline \multirow{3}{*}{ Unidade de Comunicação - UCO } & Gerente da Unidade de Comunicaçấo \\
\hline & Equipe de Marketing \\
\hline & Equipe de Eventos \\
\hline \multirow{3}{*}{$\begin{array}{l}\text { Unidade de Orçamento e Finanças - } \\
\text { UOF }\end{array}$} & Gerente da Unidade de Orçamento e Finanças \\
\hline & Equipe de Contabilidade e Programação Financeira \\
\hline & Equipe de Orçamento e Registro \\
\hline \multirow{4}{*}{$\begin{array}{l}\text { Unidade de Apoio Acadêmico e } \\
\text { Logística-UAL }\end{array}$} & Gerente da Unidade de Apoio Acadêmico e Logística \\
\hline & Equipe de Apoio Acadêmico \\
\hline & Equipe de Logística \\
\hline & Equipe de Atendimento \\
\hline \multirow{2}{*}{ Unidade de Gestão de Pessoas - UGP } & Gerente da Unidade de Gestão de Pessoas \\
\hline & Equipe de Controle e Registro \\
\hline
\end{tabular}

A estrutura acima demonstra uma organização detalhada, que foi construída ao longo do tempo em função de inúmeros projetos de EAD e da quantidade expressiva de alunos envolvidos. A realidade atual da maioria das IES brasileiras impede a estruturação de um CEAD com essa riqueza de detalhamento e de pessoal.

Uma das instituições envolvidas nessa pesquisa7 estruturou um CEAD com uma composição mais modesta, mas que procura atender as demandas iniciais dos projetos a serem executados. A Figura 1 mostra a estrutura adotada.

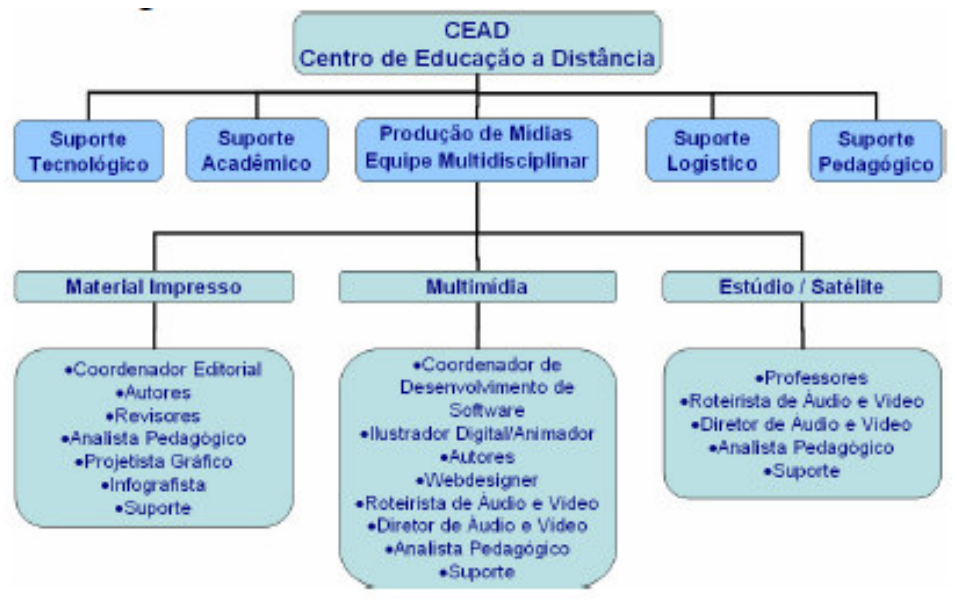

Figura 1 - Estrutura do CEAD - Proposta inicial

A composição apresentada estaria de acordo com as funções descritas no trabalho de Fabri \& Carvalho:

"Em um projeto para o desenvolvimento de uma aplicação para EAD a definição da equipe de projeto é um fator crítico na busca da qualidade, a necessidade de uma equipe multidisciplinar se faz necessária em todas as fazes de ciclo de vida do projeto. Uma equipe multidisciplinar para um projeto de EAD deve ser composta de: professores: pessoas responsáveis por criar os cursos, aulas, etc; especialista didático-pedagógico em EAD:

7 A instituição não foi identificada em função de estar se posicionando estrategicamente neste mercado extremamente competitivo da EAD no setor privado. O mesmo procedimento será adotado para outras IES envolvidas na pesquisa. 
profissional com formação pedagógica e que possui experiência projeto de EAD; engenheiro de software: profissional que insere, modela a informação no ambiente (software, por exemplo) em questão; psicólogo: profissional que tenta resolver problemas sociais, culturais entre os participantes do EAD; arquiteto da informação: profissional que constrói o curso no ambiente, este profissional seria comparado a um web-design com noções de arquitetura e semiótica; e por fim aluno que deve aprender com satisfação." (2005)

Contudo, tão importante quanto definir os papéis e funções dentro de um CEAD, é a identificação clara de todas as atividades a serem desempenhadas. O detalhamento dessas ações deve carregar informações relativas ao grau de importância, prioridade das ações, etapas de implementação das ações, custos, estratégias de emergência e rotinas de atividade (Rumble, 2003). Na realidade, um elenco de informações que permitam não só o planejamento estratégico do CEAD, mas a gestão estratégica do mesmo.

É importante esclarecer que uma mesma ação genérica, como, por exemplo, prover tutoria a distância através do ambiente virtual de aprendizagem, irá gerar desdobramentos específicos para cada cliente atendido pelo CEAD. Para o cliente eterno/aluno, serão tomadas iniciativas relacionadas a fornecer prontidão de atendimento em nível adequado, alocação de tutores com competências específicas, tanto com conhecimento especializado das disciplinas em desenvolvimento quanto tutores com conhecimento das tecnologias de TI que prestarão auxílio sobre o AVA ou

LMS utilizado. Já para o cliente interno/tutor, o desdobramento de ações será diferente, levará em conta a preparação do local onde os tutores ficarão localizados, com suas cabines de atendimento em desktops, organização da grade horária de plantões de atendimento, confecção de planilhas para preenchimento de relatórios das atividades de tutoria prestadas, as quais podem gerar recursos de FAQ disponibilizados futuramente no ambiente. Da mesma forma, para o cliente interno/gestor, serão necessários a previsão e emissão do quantitativo de horas trabalhadas para efetivar pagamentos, lista de materiais específicos de consumo, relatórios de atividades de tutoria com grau de satisfação do usuário, etc.

Os exemplos anteriores, longe de esgotar o assunto, somente esclarecem que o CEAD, como parte da organização institucional, deverá representar diferentes papéis, efetuar ações com graus diversos de prioridade e importância, e que, mesmo podendo ser descrita em termos genéricos, como no exemplo da tutoria, trarão desdobramentos específicos para cada ator inserido no sistema de EAD.

\section{Modelos diferenciados para necessidades distintas de público e de recursos}

A construção de projetos de educação a distância para a educação profissional e tecnológica encerra desafios peculiares e distintos de projetos convencionais (Schnaid ET al, 2006). A experiência dos autores ao elaborar projetos dessa natureza permitiu construir esse ponto de vista. A descrição de alguns desses projetos e suas características permitirá compreender a diversidade de soluções possíveis de EAD e da complexidade na escolha do modelo mais adequado em função das demandas específicas.

$\mathrm{O}$ primeiro exemplo de projeto de EAD foi concebido para atender a um curso superior a ser ministrado em municípios do interior estadual. A instituição requeria um modelo viável, de baixo custo, oportunizando migrar de uma experiência bem sucedida de cursos livres presenciais ministrados em fins de semana. Uma equipe de professores deslocava-se alternadamente para as localidades e ministrava seus cursos. A direção desejava manter essa dinâmica de encontros semanais com sua equipe rotativa de professores.

A solução construída foi de um modelo com presencialidade acentuada. Ao todo, 12 pólos de presença foram distribuídos em locais estratégicos do interior daquele 8 estado. Os encontros presenciais foram mantidos, requerendo um turno completo para encontro. $\mathrm{O}$ ambiente virtual de aprendizagem servia como elemento de integração para as atividades a distância. O fato da equipe de professores deslocar-se até os pólos, evitou a necessidade de 
transmissão de tele-aulas. O pólo dispõe de salas de aula convencionais, laboratório de informática e biblioteca setorial. Os professores contam com um monitor para auxílio no laboratório de informática. A Figura 2 demonstra essa solução de EAD.

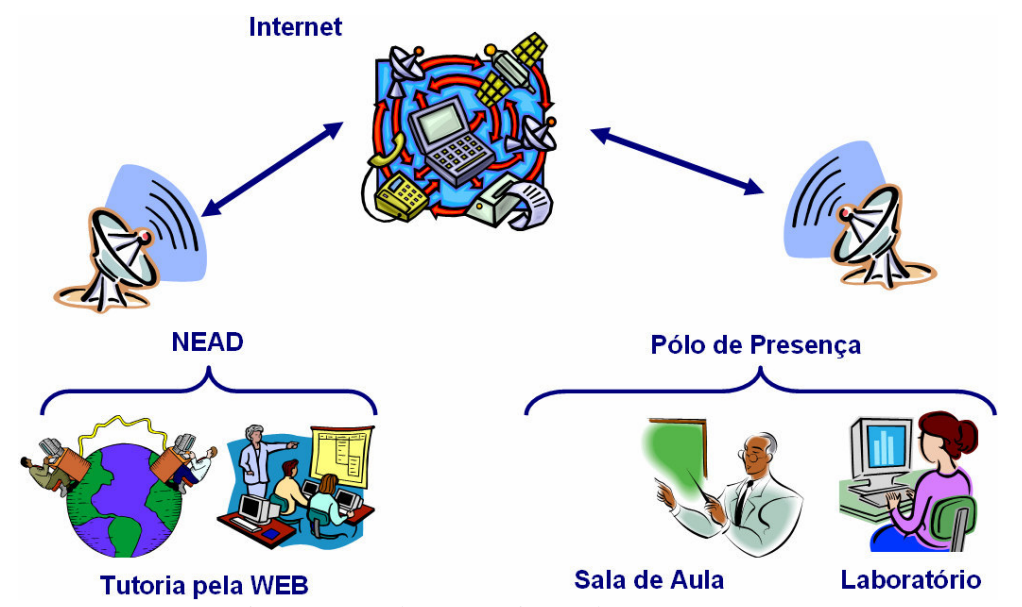

Figura 2 - Solução equipe volante para EAD

Essa solução implica em custo considerável de recursos humanos, com despesas de transporte e hospedagem, mas minimiza a exigência de infra-estrutura tecnológica

$\mathrm{m}$ locais mais carentes. Os investimentos iniciais para a instituição também foram minimizados. A Faculdade investiu na construção de um Núcleo de Educação a

Distância - NEAD, onde se situa a equipe de tutoria do ambiente virtual de aprendizagem. O ambiente virtual de aprendizagem serve de apoio e suporte para as atividades desenvolvidas ao longo da semana.

O segundo exemplo de projeto de EAD foi concebido para ter abrangência nacional, atendendo a mais de 50 pólos de presença espalhados pelo Brasil. Esta característica já inviabiliza uma solução que envolvesse o deslocamento de professores da sede até os pólos, sem que o custo ficasse proibitivo. A opção dessa IES foi por usar um sistema de transmissão de tele-aulas via satélite. O custo dessa solução é elevado e requer trabalhar com um grande número de alunos e cursos. As aulas serão gravadas em um estúdio, no tele-porto, e transmitidas para os pólos de presença. Cada pólo dispõe de infra-estrutura de recepção, com uma tele-sala adequada, salas de aula convencionais, laboratório de informática, brinquedoteca e biblioteca setorial. A Figura 3 detalha essa solução.

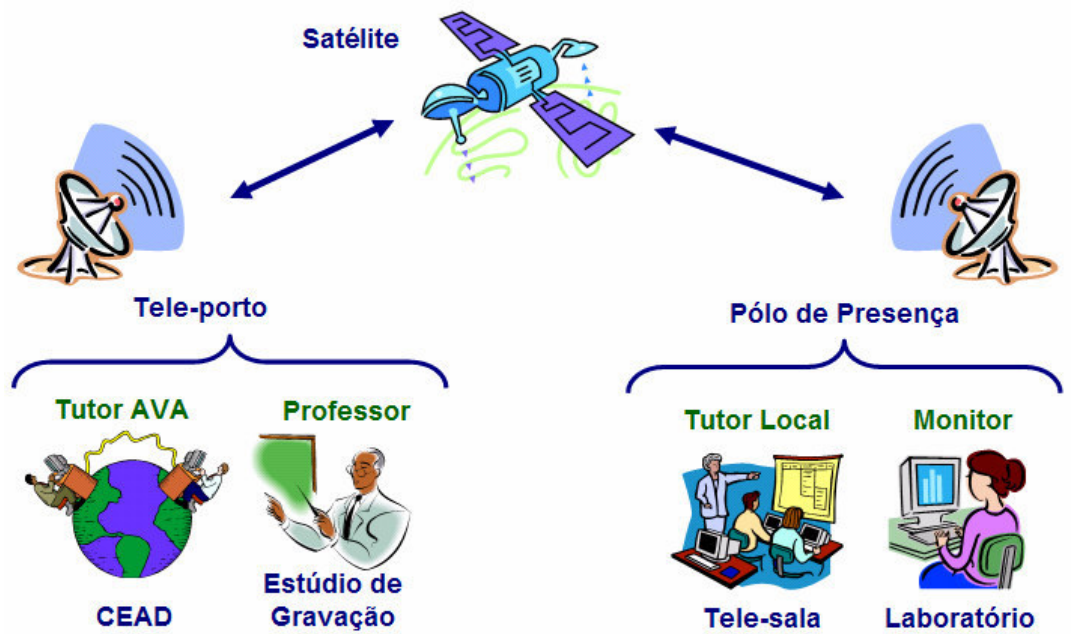

Figura 3 - Solução tele-aula por satélite para EAD 
Esse modelo de aula por satélite oportuniza a interação síncrona, através do envio de perguntas e participações pelo telefone ou pela sala de bate-papo do ambiente virtual de aprendizagem. As intervenções dos alunos são oportunizadas em momentos específicos durante a geração da tele-aula no estúdio. Nos pólos de presença existe um tutor local na tele-sala para orientação e condução das atividades coletivas, e monitor no laboratório de informática. $\mathrm{O}$ ambiente virtual de aprendizagem serve de apoio e suporte para as atividades desenvolvidas ao longo da semana, contanto com o apoio dos tutores de ambiente.

As limitações dessa solução estão relacionadas aos custos de implantação e manutenção mensais do serviço, além da obrigatoriedade de sincronismo de todas as turmas do curso gerado, reduzindo a flexibilidade de implantação de novas turmas e cursos em função da capacidade da grade de transmissão semanal, via satélite, e dos cursos em andamento. A solução exige a expansão das tele-salas no pólo, além da contratação de mais canais de satélite com os anos posteriores de funcionamento dos cursos.

O terceiro exemplo de projeto de EAD foi concebido para uma IES que planejava um curso de pós-graduação a distância, tendo experiência com a gravação de aulas e sua transmissão por vídeo streaming. Portanto, era uma solução baseada fortemente em internet, requisitando que o pólo de presença e seus alunos contassem com uma infra-estrutura adequada de acesso a internet. A Figura 4 mostra a solução de

EAD.

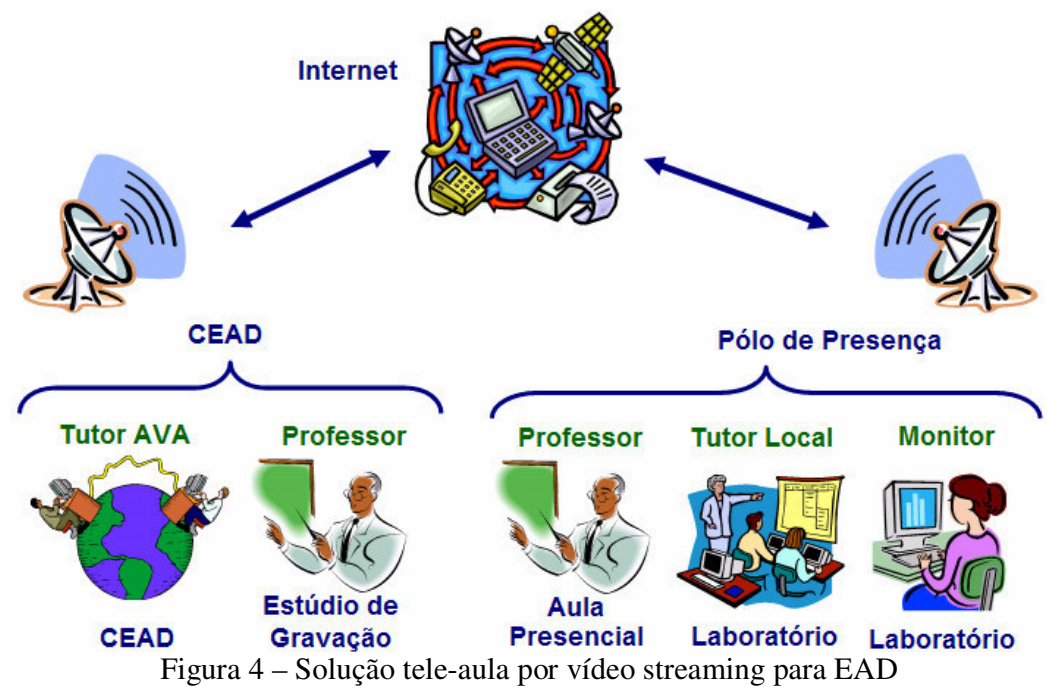

O projeto previa algumas aulas presenciais nos pólos, com a ida de professores da unidade sede até o local, o que implica despesas de deslocamento e hospedagem. O projeto é de abrangência restrita e atende um público reduzido, para conteúdos de natureza complexa. Foram previstos laboratórios específicos para ensaios, contando com tutores locais e monitores para os laboratórios de informática. As interações síncronas durante as tele-aulas são possíveis através do recurso de bate-papo (chat) disponível no AVA.

$\mathrm{O}$ ambiente virtual de aprendizagem seria utilizado no acompanhamento e envio das atividades a distância, contando com tutoria específica. As limitações desse projeto se referem a necessidade de uma infra-estrutura de servidores de streaming robusta para um público de maior abrangência. Caso o curso necessite de práticas laboratoriais específicas, o custo de implantação dos pólos e de tutoria local deve ser corretamente dimensionado. A necessidade de estúdio e sistema de geração/codificação também encarece a solução no seu estágio inicial.

O quarto exemplo de projeto de EAD foi concebido para uma IES que desejava implantar cursos de caráter mais profissionalizante, com aulas práticas de forma intensa. 
O projeto teria abrangência estadual e usaria uma cadeia de escolas como parceiras para as aulas práticas. As aulas de enfoque mais teórico seriam gravadas em estúdio e disponibilizadas em DVD, os alunos contariam com a presença de um tutor local que exibiria as aulas na TV, o acervo de vídeos também estaria disponível para acesso via streaming pela internet.

A ênfase em aulas práticas seria atendida com uma equipe volante que contaria com unidades móveis para levar os equipamentos portáteis (kits didáticos) para os pólos. Além do tutor local, os alunos contariam com os monitores nos laboratórios de informática e os instrutores para as aulas práticas.

O ambiente virtual de aprendizagem seria utilizado no acompanhamento das atividades a distância e o auxílio através dos tutores de ambiente. A Figura 5 apresenta a solução de vídeo-aula gravada e unidade móvel pra EAD.

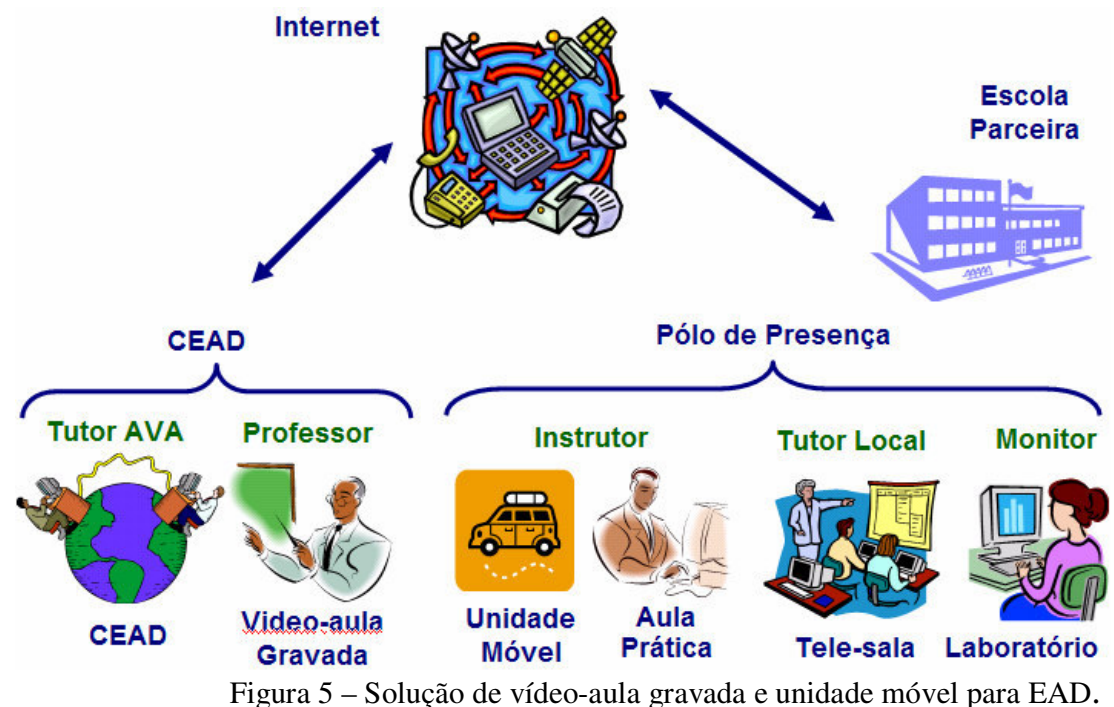

As limitações se relacionam ao custo das unidades móveis, com seus kits didáticos, e despesas de deslocamento e hospedagem dos instrutores técnicos. A logística das aulas práticas também limita ao impedir um cronograma único das aulas práticas, pois deve prever o deslocamento das unidades entre os pólos, mediante calendário prévio. Contudo, as vantagens com tal sistema são decorrentes do menor investimento inicial, se comparássemos com a compra e imobilização de laboratórios nas instituições atendidas. Vale a pena destacar que o projeto teria período de execução de 2 a 4 anos, atendida a demanda o projeto poderia ser levado a outros municípios ou estados. A confecção de kits didáticos, planejamento de práticas bem dimensionadas e a contratação de instrutores com disponibilidade de deslocamento e conhecimento especializado, podem se configurar como uma dificuldade a mais.

$\mathrm{O}$ quinto exemplo de projeto de EAD foi concebido para uma IES que montar um curso de especialização com um diferencial de mercado, adequado a um público alvo de grande poder aquisitivo. Seriam utilizados dispositivos móveis, que permitiriam o desenvolvimento de conteúdos multimídia específicos para um contexto de e-learning.

Os dispositivos móveis estariam inclusos no custo total pago pelo aluno. O projeto seria abrangência regional e usaria os pólos próximos a região metropolitana. As aulas de enfoque mais teórico seriam gravadas em estúdio e disponibilizadas para download no dispositivo móvel (PDAs, Palmtops e Smartphones), o acervo de vídeos também estaria disponível para acesso via streaming pela internet. 
Além de aulas presenciais com os professores nos pólos, os alunos contariam com os monitores nos laboratórios de informática. $\mathrm{O}$ ambiente virtual de aprendizagem seria utilizado no acompanhamento das atividades a distância e o auxílio dado através dos tutores de ambiente. A Figura 6 apresenta a solução de vídeo-aula gravada e dispositivo móvel (mobile).

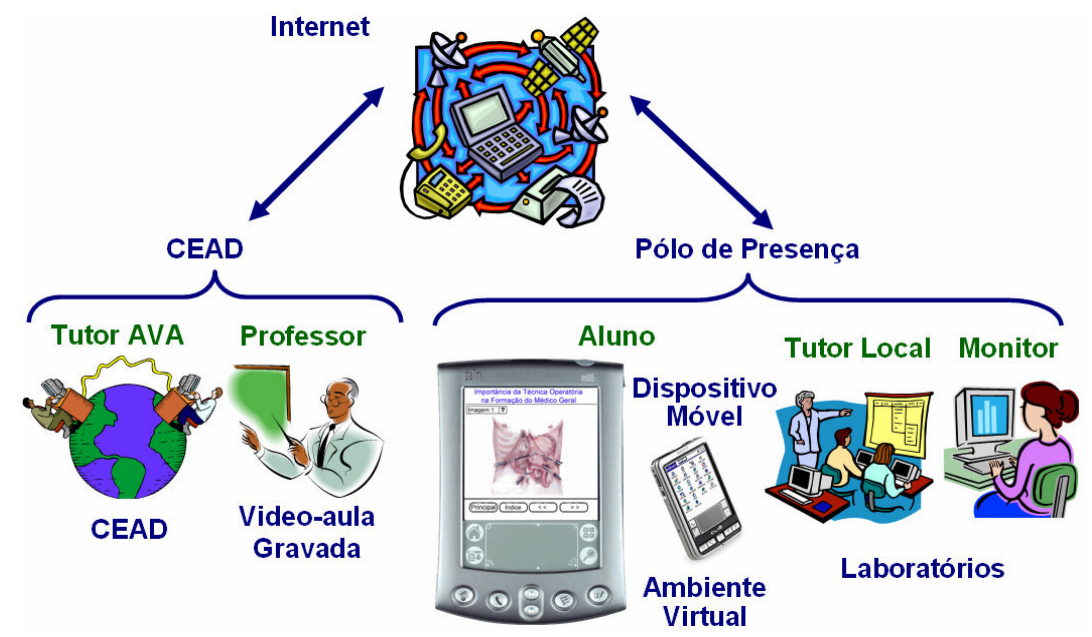

Figura 6 - Solução de vídeo-aula gravada e dispositivo móvel (mobile).

As limitações dessa solução seriam decorrentes dos investimentos iniciais, não só relativos ao custo do dispositivo móvel, mas da equipe e do esforço de desenvolvimento para uma área emergente, como é a de m-learning (Meireles et al., 2005). A opção em fornecer o dispositivo móvel está relacionada aos problemas de portabilidade para diferentes marcas. Será necessária também uma infra-estrutura de TI nos pólos que permita a sincronização dos dispositivos via rede wireless (Wi-Fi, Bluetooth), oportunizando o download de arquivos e upload de dados (exercícios, planilhas e relatórios). As vantagens dessa estrutura se relacionam a possibilidade de utilizarem-se ambientes virtuais de aprendizagem, com exercícios, simulações e vídeos, que poderiam ser explorados pelos estudantes em qualquer lugar e momento. Essa flexibilidade é desejável a profissionais de grupos corporativos ou que necessitam viajar com freqüência, e que poderiam se beneficiar de ambientes de aprendizagem que aliem mobilidade e conectividade sem fio.

As experiências dos autores nas ações de estruturação e capacitação de equipes de CEADs revelaram que os docentes encontram dificuldades acentuadas na escolha $\mathrm{e}$ dimensionamento das tarefas de EAD, na seleção dos conteúdos a serem abordados na teleaula, nos exercícios propostos como atividades supervisionadas ou individuais. O problema foi minimizado com os cursos de capacitação continuada executados pelos CEADs das instituições, e depois com o apoio constante e sistemático dado aos professores pela equipe multidisciplinar do CEAD. Também foi desenvolvida uma ferramenta para auxiliar no planejamento das atividades de educação a distância, o Plano Operacional Curricular - POC. Ele mostrou-se extremamente útil ao permitir que os professores efetuassem o planejamento no tempo de suas disciplinas. A idéia de empregar as fichas de planejamento surgiu nos Cursos de Capacitação de Professores e

Tutores para EAD, ministrados pelos autores. O resultado obtido foi favorável e o emprego das fichas adotado pelas instituições que desenvolveram os projetos acima. A ficha permite que o professor efetue o planejamento de cada unidade temática em separado, dimensionando o período de tempo necessário para a execução de cada uma.

A Figura 7 mostra um exemplo do POC. 


\begin{tabular}{|c|c|c|c|c|c|c|c|c|c|}
\hline \multicolumn{4}{|l|}{ Disciplina XXX } & \multicolumn{2}{|c|}{ Carga Horária Total: X h } & \multicolumn{3}{|c|}{$N^{0}$ de Semanas: } & \multirow{3}{*}{$\begin{array}{c}\mathrm{X} \\
\mathrm{X} \\
\mathrm{AI}\end{array}$} \\
\hline & & & & & \multicolumn{4}{|c|}{ Disciplinas no Semestre: } & \\
\hline \multirow{3}{*}{ Distribuição Programática } & & $\mathrm{TL}$ & AS & AI & \multirow{3}{*}{\multicolumn{2}{|c|}{$\begin{array}{c}\text { Presencialidade Semanal } \\
\text { Disponível }\end{array}$}} & $\mathrm{TL}$ & AS & \\
\hline & Total & $\mathrm{X} \mathrm{h/a}$ & $\mathrm{X} \mathrm{h} / \mathrm{a}$ & $\mathrm{X} \mathrm{h/a}$ & & & $\mathrm{x}$ & & \\
\hline & Semanal & $\mathrm{xp} / \mathrm{a}$ & $\mathrm{X} \mathrm{h} / \mathrm{a}$ & $\mathrm{X} \mathrm{h/a}$ & & & $\mathrm{And}$ & A nd & $1 \mathrm{i} / \mathrm{a}$ \\
\hline Unidade Temática 1 & \multicolumn{4}{|c|}{$\mathrm{XXX}$} & Semana $\mathrm{X}^{\circ}$ & \multicolumn{2}{|c|}{ Carga Horária Total } & \multicolumn{2}{|c|}{$\mathrm{X} \mathrm{h}$} \\
\hline Tópicos & \multicolumn{9}{|l|}{ - $x x x$} \\
\hline $\begin{array}{l}\text { Apresentaçấo de conteúdos } \\
\text { Tele-aula (TL) interativa }\end{array}$ & \multicolumn{9}{|l|}{ 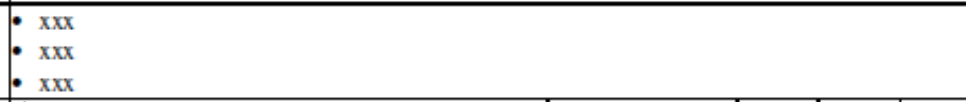 } \\
\hline \multirow{2}{*}{$\begin{array}{l}\text { Atividades Supervisionadas } \\
\text { (AS) }\end{array}$} & \multirow{2}{*}{\multicolumn{3}{|c|}{$\begin{array}{ll}\cdot & x x x \\
- & x x x\end{array}$}} & & & \multirow{2}{*}{$\begin{array}{l}\text { Presencialidade } \\
\text { Prevista }\end{array}$} & $\mathrm{Xh} / \mathrm{a}$ & $\mathrm{Xh} / \mathrm{a}$ & Não \\
\hline & & & & & & & & & \\
\hline Atividades Individuais (AI) & $\cdot x x x$ & & & & & & & & \\
\hline Práticas Laboratoriais & $\cdot x x x$ & & & & & & & & \\
\hline Textos Operacionais & $\cdot x x x$ & & & & & & & & \\
\hline Leituras Complementares & $\begin{array}{l}x x x \\
- \\
x x x\end{array}$ & & & & & & & & \\
\hline Bibliografia & - $\mathrm{xxx}$ & & & & & & & & \\
\hline Sites de Interesse & $\begin{array}{l}\text { - http:/// } \\
\text { - http:// }\end{array}$ & $\begin{array}{l}\text { www. } \\
\text { www. }\end{array}$ & & & & & & & \\
\hline
\end{tabular}

Figura 7 - Modelo de Plano Operacional Curricular - POC para EAD

Todas as soluções mostradas acima foram desenvolvidas para instituições que iriam desenvolver cursos para a educação profissional e tecnológica. Os cursos atendiam a uma ampla gama de níveis, desde o ensino técnico, cursos superiores de tecnologia, bacharelados e pós-graduação. Os cursos se configuravam no cenário de conteúdos de natureza complexa e alta exigência cognitiva, próprios da área mais tecnológica.

Vale a pena destacar que as soluções propostas não estavam relacionadas a uma abordagem ou modelo pedagógico específico. O foco desta pesquisa está para a compreensão das soluções de educação a distância num sentido mais amplo, que propicie liberdade para a implantação de diversos modelos pedagógicos, de acordo com a natureza dos públicos atendidos, da natureza dos cursos e seus conteúdos, e da filosofia e trajetória históricoeducacional da instituição.

\section{Conclusões}

O trabalho refletiu sobre a importância da estruturação de um setor para desenvolver instrumentos de planejamento e gestão dos cursos a distância, de acordo com necessidades específicas da instituição, levando-se em conta múltiplos cursos, públicos e níveis, bem como a gestão dos clientes internos da instituição (equipe de professores, produtores de mídia, tutores, etc.) Foram apresentadas questões relativas à estruturação de um setor como este (chamado CEAD, de forma geral), e a seguir foram apresentados modelos de cursos à distância para situações diferenciadas.

As soluções descritas não dão conta de todas as necessidades de EAD para a educação profissional e tecnológica. A posição dos autores é que as soluções devem ser construídas caso a caso, evitando a armadilha de conformarem-se todas as demandas a modelos rígidos. $\mathrm{O}$ CEAD deve ter como característica o fornecimento de soluções flexíveis e customizadas para a instituição, equacionando de maneira precisa a relação custo $\mathrm{x}$ benefício, sem perder $\mathrm{o}$ foco das questões pedagógicas e, principalmente, da natureza dos conteúdos complexos e de exigência cognitiva elevada.

\section{Referências Bibliográficas}


CHENG, Lin Chih; FILHO, Leonel Del Rey de Melo. QFD: desdobramento da função qualidade na gestão de desenvolvimento de produtos. São Paulo: Editora Blücher, 2007.

FABRI, José Augusto; CARVALHO, Marly Monteiro de. QFD Estendido em ambiente de gerenciamento de informações para ensino a distância. Revista Produção Online.

ISSN1676-1901, Vol. 5, Num.2, Junho de 2005. Disponível em:

http://www.producaoonline.ufsc.br/v05n02/artigos/205_2005.htm Acesso em 13/02/2007.

FREEMAN, Richard. Planejamento de sistemas de educação à distância: Um manual para decisores. The Commonwealth of Learning - COL. Vancouver, Canadá,

2003. Disponível em: < http://www.col.org/> Acesso em: 10/01/2007.

MEC/SEED. Referenciais de qualidade para cursos de graduação a distância. Brasília, DF: 2003. Disponível em: < http://portal.mec.gov.br/seed/arquivos/pdf/ ReferenciaisdeEAD.pdf> Acesso em: 11/02/2007.

MEIRELLES, L.F.; TAROUCO, L.M.R.; SILVA, G.D.G. Framework para Aprendizagem com Mobilidade. In: Simpósio Brasileiro de Informática na Educação, 16., 2005, Juiz de Fora. Anais. Juiz de Fora: Sociedade Brasileira de Computação / Universidade Federal de Juiz de Fora.

MOORE, M. G.; KEARSELY, G. Distance Education: Systems View. Wadsworth Publishing Company, 1996.

PERRY, Gabriela Trindade; TIMM, Maria Isabel; FERREIRA, Raymundo Carlos Filho; SCHNAID, Fernando; ZARO, Milton Antonio. Desafios da gestão de EAD: necessidades específicas para o ensino científico e tecnológico. RENOTE: Revista Novas Tecnologias na Educação. V.4 Nº1, Julho, 2006. CINTED. Universidade Federal do Rio Grande do Sul. 2006. RIBEIRO, Luis Otoni Meireles; TIMM, Maria Isabel; ZARO, Milton Antonio. Laboratórios Didáticos Virtuais Baseados em Modificações de Jogos (Modgames) e seu Uso na EAD. In: SBIE 2005 - XVI Simpósio Brasileiro de Informática na Educação, Workshop de Arquiteturas Pedagógicas para Suporte a Educação a Distância Mediada pela Internet, 2005, Juiz de Fora, 2005.

RIBEIRO, Luis Otoni Meireles; TIMM, Maria Isabel ; ZARO, Milton Antonio . The Limits on Simulation of Realistic Physics for Construction of Virtual Laboratory, Based in Mod-Games, in Engineering and Technology Education.. In: WCCSETE'2006 World Congress on Computer Science, Engineering and Technology Education, 2006, Itanhaem-Santos.

WCCSETE'2006 World Congress on Computer Science, Engineering and Technology Education, 2006.

RUMBLE, Greville. A gestão dos sistemas de ensino a distância. Brasília: Editora Universidade de Brasília: UNESCO, 2003.

SCHNAID, Fernando; ZARO, Milton Antonio; TIMM, Maria Isabel (ORGs). Ensino de engenharia: do positivismo à construção das mudanças para o século XXI. Porto Alegre: Editora da UFRGS, 2006. 